This document is the accepted manuscript version of the following article:

Allegrini, J., \& Carmeliet, J. (2017). Simulations of local heat islands in Zürich with coupled CFD and building energy models. Urban Climate, (20 pp.). http://doi.org/10.1016/j.uclim.2017.02.003

This manuscript version is made available under the CC-BY-NC-ND 4.0 license http://creativecommons.org/licenses/by-nc-nd/4.0/

\title{
Simulations of local heat islands in Zürich with coupled CFD and building energy models
}

\author{
Jonas Allegrini ${ }^{\mathrm{a}, \mathrm{b}^{*}}$, Jan Carmeliet ${ }^{\mathrm{a}, \mathrm{b}}$ \\ ${ }^{a}$ Laboratory for Multiscale Studies in Building Physics \\ Swiss Federal Laboratories for Materials Science and Technology (Empa) \\ Überlandstrasse 129, 8600 Dübendorf, Switzerland \\ ${ }^{b}$ Chair of Building Physics, Swiss Federal Institute of Technology Zurich (ETHZ), \\ Stefano-Franscini-Platz 5, 8093 Zürich, Switzerland
}

\section{Abstract:}

Due to the urban heat island (UHI) effect the air temperatures in urban areas are most of the time higher compared to the temperatures in rural areas. Further the wind speeds are lower due to wind sheltering. In the past decades cities and therefore also the urban heat islands have been continuously growing. The local microclimate has a strong impact on the energy demand of buildings and the human comfort and health. Only few guidelines exist for urban planners to mitigate UHI effects or its impacts. This study aims at simulating the effect of new buildings on the local urban microclimate for a building site in Zürich (Switzerland). One-way coupled CFD and building energy simulations are conducted to determine the increase in air and surface temperatures due the presences of new buildings. The daytime local air temperatures for weather conditions with high ambient air temperatures, which are considered to be most critical for thermal comfort, are studied. The results show that the formation of local hot spots strongly depend on the building geometries, building materials, the strength of buoyancy and the wind directions and wind speeds.

\section{Keywords}

Urban heat island effect, CFD, Building energy simulation, Thermal comfort, Microclimate, Urban design

Corresponding author: Jonas Allegrini, Empa Dübendorf, Ueberlandstrasse 129, 8600 Dübendorf, Switzerland. Tel.: +41 (0) 587656512 , Fax: +41 (0) 5876540 09, e-mail: jonas.allegrini@empa.ch

\section{Introduction}

The microclimate in urban areas differs significantly from the climate in rural areas. Wind speeds are lower due to wind sheltering leading to less removal of heat and pollutants from urban areas (Oke 1987) and air temperatures are higher due to the urban heat island effect. In London measurements showed up to $7 \mathrm{~K}$ higher air temperatures at night-time in the city compared to measurements outside the city (Watkins et al. 2002). The mean heat island intensity exceeds $10 \mathrm{~K}$ (Santamouris et al. 2001) in Athens. Also for cities in Switzerland significant urban heat island intensities were measured (Wanner and Hertig 1983). For the city of Zürich maximum urban heat island intensities 
of 5-7 ${ }^{\circ} \mathrm{C}$ (Basel: $5-6^{\circ} \mathrm{C}$, Berne: $5-6^{\circ} \mathrm{C}$, Biel: $4-5^{\circ} \mathrm{C}$, Freiburg: $3-5^{\circ} \mathrm{C}$ ) were already observed by Wanner and Hertig (1983) about 30-35 years ago. The urban microclimate influences strongly the energy demand for space cooling and heating of buildings (e.g. Allegrini et al. 2012a, Bouyer et al. 2011), and it has also a large impact on the thermal comfort (e.g. Saneinejad et al. 2014) and health (e.g. Robine et al. 2008) of the people living in urban areas. Global warming and associated heat waves (Schär et al. 2004, Fischer and Schär 2009) may further increase the temperatures in urban areas. It was shown by Li and Bou-Zeid (2013) that the combined effect of UHI and heat waves is larger than the sum of the two individual effects. This can reduce the potential for night cooling significantly, what might have a strong impact on the space cooling demands in Switzerland, where mainly passive night ventilation is used to cool the buildings (Frank 2005).

Knowledge of the detailed urban microclimate is important to predict space cooling demands or the thermal comfort. To get accurate results from building energy simulations, accurate microclimatic data at the building site are needed. Further, city planners need finely resolved information on the local microclimate to improve the exterior thermal comfort for planning new urban areas with high thermal comfort. Numerical simulations can be used to predict and study the local microclimate at the neighbourhood scale. A large number of numerical studies on the microclimate can be found in literature. Overviews of microclimate studies are given by Arnfield (2003), Mirzaei and Haghighat (2010) and Moonen et al. (2012). The local urban microclimate is numerically studied with different degrees of complexity in literature. In a large number of studies ENVI-met (Bruse and Fleer 1998) is used to simulate the urban microclimate (eg. Ali-Toudert and Mayer 2006, Perini and Magliocco, Taleghani et al. 2014). ENVI-met is a model to simulate flows around buildings, model turbulence, exchange processes of heat and vapour at buildings and vegetation, bioclimatology and pollutant dispersion (Bruse and Fleer 1998) with rather low spatial resolution. To get a higher spatial resolution and to be able to determine the convective heat transfer at the building façades Saneinejad et al. 2012 conducted CFD (Computational Fluid Dynamics) simulations coupled with a detailed radiation model and a detailed heat and moisture transport model for a two-dimensional urban street canyon. They studied local heat island mitigation measures with their coupled simulations. Studies with a similar approach have been conducted to investigate the influence of the local microclimate on the space cooling demand of buildings in urban areas (eg. Allegrini et al. 2012a and Bouyer et al. 2011). The authors of these studies concluded that it is important to account for the local urban microclimate when simulating energy demands of buildings with building energy simulations. Allegrini et al. (2012a) conducted their study for a simplified urban street canyon configuration, while Bouyer et al. 2011 studied the energy demand for an urban neighbourhood with complex geometries.

Recent microclimate studies based on CFD simulations have been conducted e.g. by Toparlar et al. (2015), Gromke et al. (2015), Allegrini et al. (2015a) and Allegrini et al. (2015b). Allegrini et al. (2015a) studied the impact of different urban morphologies on the local microclimate in urban neighbourhoods. Their results showed that building geometries strongly influence the formation of local heat islands. High local heat island intensities can mainly be found in areas with decreased 
ventilation (e.g. inside courtyards). They also found a strong impact of buoyancy on the local air temperature for weather conditions with calm winds. Buoyancy was found to increase the ventilation and therefore leading to decreased air temperatures. Therefore counterintuitively they found lower local air temperatures at the pedestrian level for lower wind speeds. The results from the same simulations were used in a second publication (Allegrini et al. 2015b) to study heat fluxes in urban areas. By studying the heat fluxes, they could better understand how heat is removed from urban areas. They found that turbulence is an important mechanism to remove heat for weather conditions with high wind speeds, because in this case heat is transported by turbulence through shear layers that are formed around buildings. For weather conditions with low wind speeds the shear layers are less important, because the flow is mainly driven by buoyancy and therefore convective heat fluxes are more important for these weather conditions. In Allegrini et al. (2015a) and Allegrini et al. (2015b) an approach with on-way coupled CFD (computational fluid dynamics) and building energy simulations (BES) is used to determine the air and surface temperatures. The surface temperatures determined in the BES are used in the CFD simulations as temperature boundary conditions. The same approach is also used in this paper. In this paper geometries of an urban neighbourhood together with existing designs for new buildings are used instead of the generic urban morphologies presented in Allegrini et al. (2015a) and Allegrini et al. (2015b).

In literature two types of wind flow or microclimate studies can be found: studies with generic building configurations (a list of a number of studies is given in Ramponi et al. 2015) and studies for existing mostly complex building configurations (e.g. Toparlar et al. 2015, van Hooff and Blocken 2010). Studies with generic building configurations can give more general results and conclusions, while the studies with more complex building geometries show complex interactions of different physical phenomena and parameters. Comparative studies of local heat islands for generic and complex building geometries allow to transfer observations from generic to more complex geometries and to evaluate the applicability of general conclusions from studies with generic building configurations to real urban environments. There exist only few studies, where generic as well as complex geometries are studied (e.g. Tominaga 2012).

In this paper a case study for complex building configuration is presented with the aim of supporting some more general findings. The focus of this study is on the daytime thermal comfort of pedestrians in summer in an urban area in the city of Zürich, Switzerland. Therefore local air temperatures are studied for a weather condition with high ambient air temperatures. A building site is chosen for this study, where the city of Zürich is planning to construct new buildings in the near future. Two designs for a group of 5-9 buildings are used in this study. The coupled CFD-BES simulations are conducted for two different wind speeds and two different wind directions. To study the influence of the colour of building materials the simulations are repeated for building envelopes with two different albedo values. The surfaces temperatures of the buildings and the local air temperatures as well as wind flow structures are analysed and discussed in this paper. The results of this case study are compared to the more general conclusions presented in the papers by Allegrini et al. 2015a and Allegrini et al. 2015b. Mainly the impact of buoyancy is compared. In addition, the ap- 
plicability of conclusions as obtained for different urban morphologies as presented in Allegrini et al. 2015 is discussed.

The structure of the paper is as follows. The building configurations studied in this paper are given in Section 2. In Section 3 and Section 4 the numerical models of BES and CFD are presented. In Section 5 the results are presented and discussed in detail. First the surface temperatures determined with BES for the different configurations are compared. Then results of CFD simulations are presented for different weather conditions and building configurations. In Section 6 the limitations of this study are discussed and in Section 7 the conclusions are drawn.

\section{Configurations}

This microclimate study is conducted for a building site in the city of Zürich (Switzerland). A satellite picture of the building site is given in Figure 1. The building site ( 6.5 hectare) is located outside the city centre at the border of an area with rather dense office buildings and single family homes. The city of Zürich is planning to densify the area of the building site by building new residential and office buildings. Architects developed two possible designs for a group of 5-9 large buildings (design A and design B in Figure 1). Some important dimensions of the buildings are given in Figure 1. The height of the tallest buildings is $60 \mathrm{~m}$ for design $\mathrm{A}$ and $70 \mathrm{~m}$ for design $\mathrm{B}$. With the new buildings a street canyon with a width of $50-65 \mathrm{~m}$ is formed. The length of this street canyon is $665 \mathrm{~m}$ for design $\mathrm{A}$ and $635 \mathrm{~m}$ for design $\mathrm{B}$. Amongst others the architects had to consider the microclimate when they developed their designs. They had to make sure that the local heat islands intensities in the total area do not increase after constructing the new buildings. In this paper the performance of the two designs is evaluated with coupled CFD-BES simulations. The building site is rather long and narrow and the main orientation of the buildings is directed by the form of the building site. Therefore the design possibilities are rather limited. East of the building site there is a neighbourhood with relatively large buildings. These buildings have heights that are comparable to the buildings of design $\mathrm{A}$ and $\mathrm{B}$ and the neighbourhood has a similar density. West of the building site there is a neighbourhood with relatively small low-rise buildings and a railway line. design A consists of five buildings. Four of the buildings are elongated and between $130 \mathrm{~m}$ and $170 \mathrm{~m}$ long. There are three $60 \mathrm{~m}$ tall towers, which are part of the elongated buildings. Three buildings consist of two long parallel parts, which are connected. Between the parallel parts there are spaces that are similar to courtyards. Except the three towers the buildings are $10 \mathrm{~m}-30 \mathrm{~m}$ tall. There are nine buildings in design B. Two of them are rather small and separated from the other buildings. Compared to design A there are larger differences in the geometries between the individual buildings. There is only one tower that is $70 \mathrm{~m}$ tall. All the other buildings are between $12 \mathrm{~m}$ and $32 \mathrm{~m}$ tall. Also for design B spaces with a courtyards shape can be found. There is an open space between the existing buildings, which is part of the building site. For both designs this space is kept open to allow the air flowing through from the railway line to the street canyon to increase the wind flow through the building site. For design A the wind can directly flow through the open space into the 

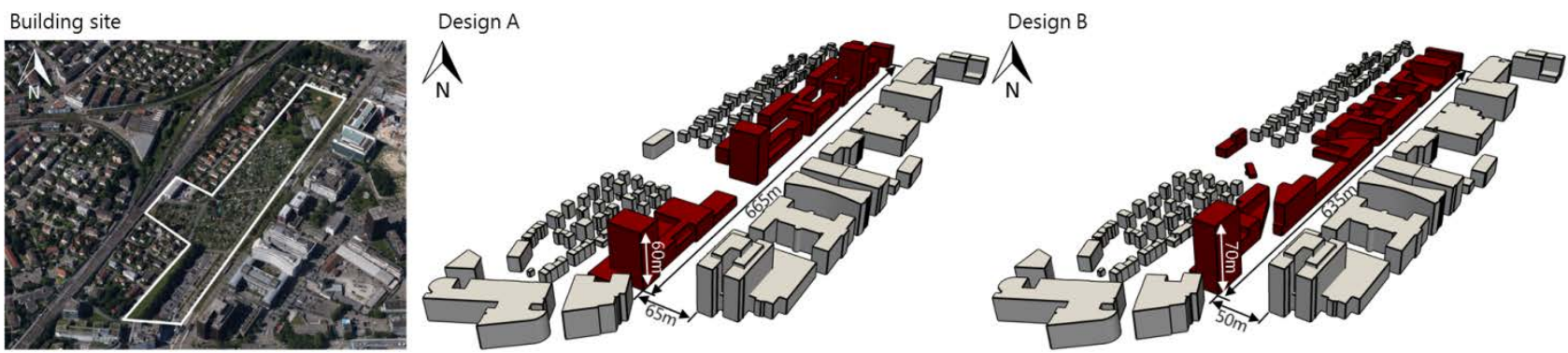

Figure 1: Satellite image of the building site in Zürich and two possible designs of building geometries.

The aim of the City of Zürich was to study the performance of the two designs and to decide based on the results, which designs would lead to the most comfortable local microclimate. An aim is also to formulate guidelines for urban planners from the analysis. In total twelve coupled simulations are conducted. The simulations are conducted for two wind directions, two wind speeds, two different albedo values for the building surfaces and the two designs. Northerly and westerly winds are chosen based on weather data measured at a nearby weather station.

\section{Numerical model}

For the study presented in this paper all building energy simulations are conducted for the climate of Zürich (Switzerland). All buildings are modelled as office buildings with corresponding occupancies and internal gains (SIA 2006). Ventilation and infiltration are considered. The glazing (Gvalue: 0.7 , U-value: $1.1 \mathrm{~W} / \mathrm{m}^{2} \mathrm{~K}$ ) fraction of the buildings is $35 \%$. Two values for the solar reflectance or albedo are used (0.2 and 0.6$)$ to study the influence of the building materials on the local heat islands. For each simulation all building surfaces have the same solar reflectance. All building surfaces have an emissivity of 0.9 . The walls have a $U$-value of $0.17 \mathrm{~W} / \mathrm{m}^{2} \mathrm{~K}$ (with outer insulation), the roofs have a U-value of $0.29 \mathrm{~W} / \mathrm{m}^{2} \mathrm{~K}$ and the ground floors a U-value of $0.3 \mathrm{~W} / \mathrm{m}^{2} \mathrm{~K}$. External shading devices are used to protect the buildings from solar gains. They close when the solar irradiation on the corresponding façade is $>150 \mathrm{~W} / \mathrm{m}^{2}$ and reopen when it is $<50 \mathrm{~W} / \mathrm{m}^{2}$. Each building consists of the same number of thermal zones as the number of exterior surfaces (walls or roofs) it has. Each thermal zone consists of one exterior surface and the associated part of the building volume. All thermal zones are assumed to have the same inside air temperature. Space heating and space cooling are used to keep the inside air temperature between $21^{\circ} \mathrm{C}$ and $26^{\circ} \mathrm{C}$ respectively.

CFD simulations are conducted for a weather condition with a rather high ambient temperature of $25.5^{\circ} \mathrm{C}$. The building site and the surrounding neighbourhoods are not totally flat, but are modelled as flat for the simulations. At the inlet of the computational domain vertical profiles of the mean horizontal wind speed, the turbulent kinetic energy and the turbulence dissipation are imposed for two reference wind speeds, $1 \mathrm{~m} / \mathrm{s}$ and $5 \mathrm{~m} / \mathrm{s}$ at $10 \mathrm{~m}$ height. These profiles represent a neutral atmospheric boundary layer, where the turbulence originates only from friction and shear (Richards and Hoxey 1993):

$$
U(y)=\frac{u_{A B L}^{*}}{k} \ln \left(\frac{y+z_{0}}{z_{0}}\right)
$$




$$
k(y)=\frac{u_{A B L}^{*}}{\sqrt{C_{\mu}}}
$$

$$
\varepsilon(y)=\frac{u_{A B L}^{*}}{k\left(y+z_{0}\right)}
$$

Here $\mathrm{u}_{\mathrm{ABL}} *$ is the atmospheric boundary layer friction velocity, $\mathrm{y}$ the height above the ground, $\mathrm{z}_{0}$ the aerodynamic roughness length, $\mathrm{k}$ the turbulent kinetic energy, $\varepsilon$ the turbulence dissipation rate, $\mathrm{U}$ the mean streamwise velocity and $\mathrm{C}_{\mu}$ a constant of the turbulence model.

At the sides and top of the computational domain a symmetry boundary condition is applied. At the outlet an outflow boundary condition is used, which assumes that there are no streamwise gradients at the outlet.

To couple the CFD and BES model the building surface temperatures ( $\left.T_{\text {surf }}\right)$ simulated with the BES are used in CFD as boundary conditions. A sketch of the coupling procedure is given in Figure 2. The surface temperatures are only transferred for the building surfaces of the new designs (design A and design B). The ground surface and the building surfaces of the already existing buildings (grey buildings in Figure 2) are modelled to have ambient temperature. The reason for that choice is that air would already heat up upstream of the new buildings, if the ground and the already existing buildings would have temperatures that are higher than the ambient air temperature. This would lead to the problem that the local air temperatures at the building site would be dependent on the size of the computational domain. With the approach used in this study not the local air temperatures are determined, but only the temperature increase due to the presence of new buildings. We remark that our approach is a simplified method, which allows to compare different designs of new buildings, by evaluation of how a certain building setting locally heats up the air and contributes to its local heat island effect. A more complete approach needs the modelling of the total surrounding neighbourhood taking also into account the global urban heat island effect, which would be too demanding from a computational perspective, and which is beyond the scope of this paper. As a consequence only temperature differences are presented in this paper and not the air temperatures itself. For the near-wall modelling, standard wall functions (Launder and Spalding 1974) with no-slip boundary condition are used as a compromise between and accuracy and computational cost. The standard wall functions are commonly used for CFD simulations of urban areas, although it is known that the use of wall function can lead to an overestimation of the convective heat flux at the building facades and subsequently to an overestimation of the local air temperatures (Allegrini et al. $2012 b$ ). For accurate heat transfer predictions very fine meshes close to surfaces are needed, but with these meshes the surface roughness cannot be accurately modelled, because the cells height has to be much higher than the roughness. Therefore, in this study walls are modelled as smooth walls, what can lead to an underestimation of the connective heat transfer. Since the aim of this study is not a detailed quantification of air temperatures and heat fluxes for a specific case, but the comparison of them for different cases for which the same models with the same limitations are used, the possible over or underestimation can be accepted. Figure 2 also shows which buildings of the urban neighbourhood are considered in the BES and CFD simulations. For the BES fewer build- 
ings are modelled, because the neighbouring buildings are only important for the radiation exchange (solar and thermal radiation). Therefore only buildings, which have an impact on the radiation balance of the buildings of the new designs, are modelled in the simulations. For the CFD simulations also buildings further up or downstream of the studied area have an impact on the flow structures and therefore more buildings are considered in the CFD simulations.

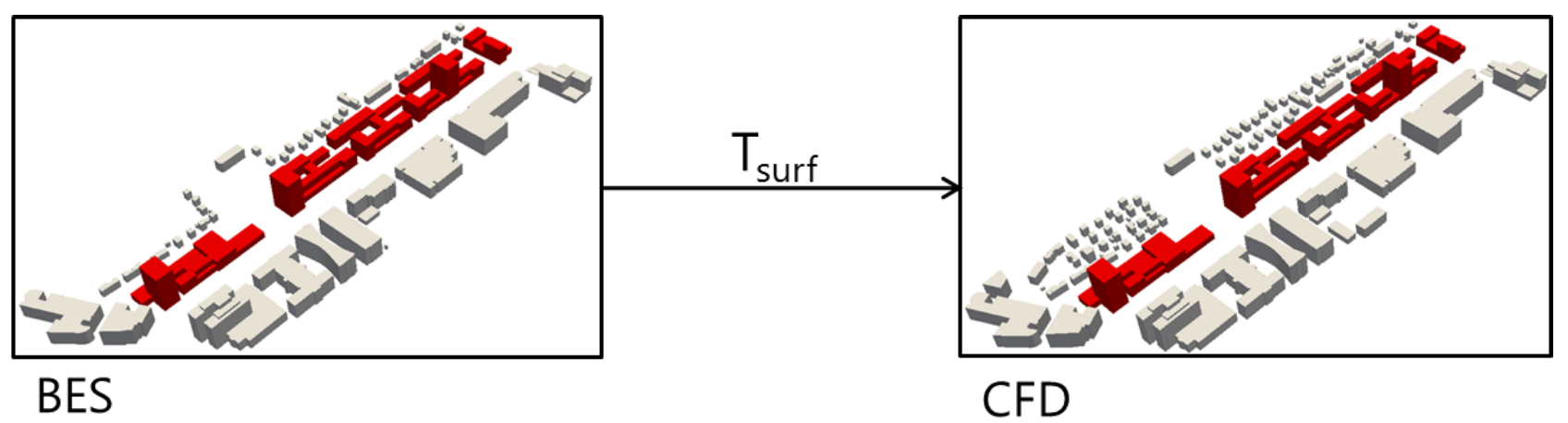

227

228

229

230

231

232

233

234

235

Figure 2: Sketch of the one-way coupling procedure. The sketch shows, which neighboring buildings are considered in the BES and CFD simulations.

Structured grids are built based on a grid sensitivity analysis and the best practice guidelines by Franke et al. (2011) and Tominaga et al. (2008). The grids are refined towards the walls to resolve the boundary layers. They consist of $7.5-10$ million cells. For the lower wind speed used in this study, the $\mathrm{y}+$ values were $<500$; for the higher wind speed, $\mathrm{y}+$ values up to 1300 can locally be found. It was verified that these rather high $y+$ values did not cause grid dependent results for the wind speeds and air temperatures. A part of the computational grid is given in Figure 3.

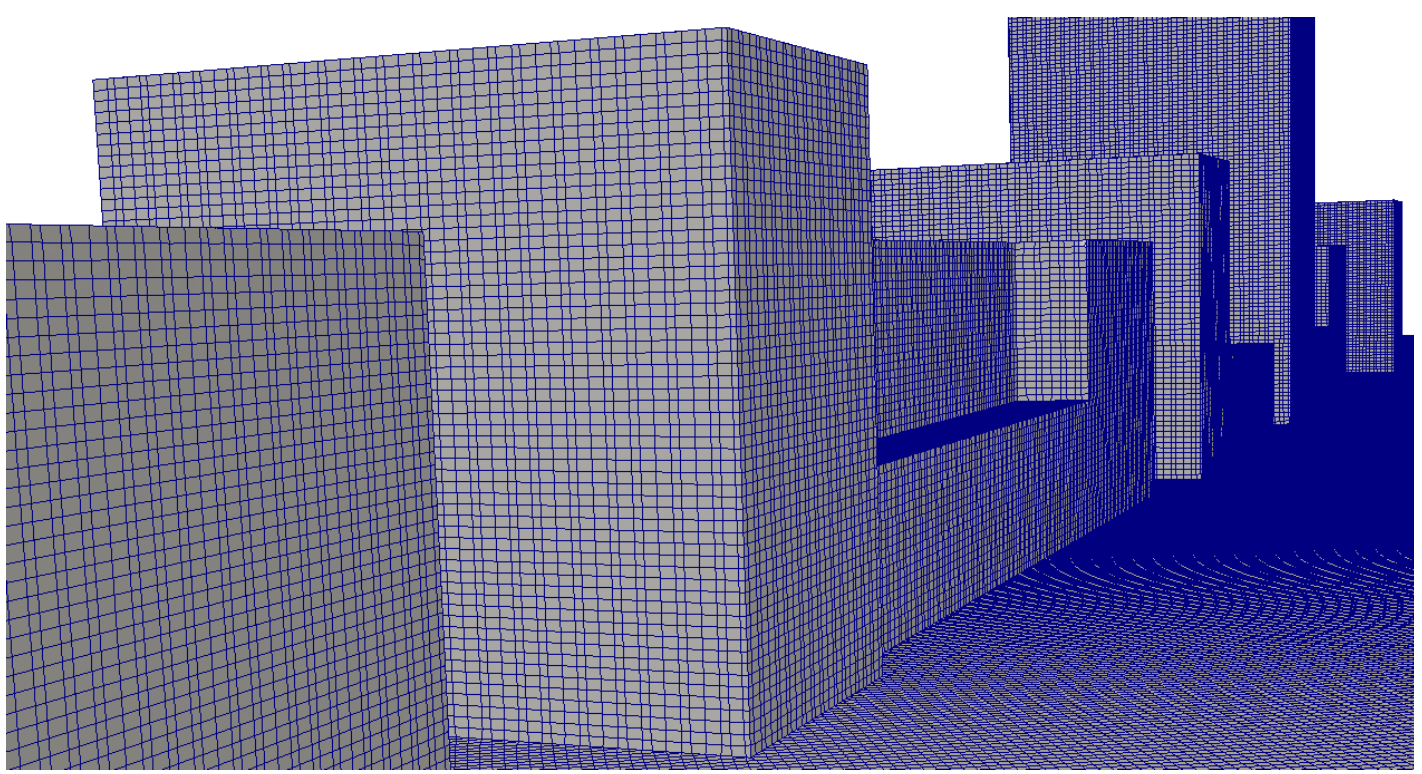

Figure 3: Computational grid on some of the buildings of design A. 
241 For the BES CitySim (Kämpf 2009, Halid and Robinson 2011 and Robinson 2011) is used. A veri-

242 fication of CitySim was conducted using BESTEST (Walter and Kämpf 2015). CitySim is a simula-

243 tion tool which models the energy fluxes in a quarter, with size ranging from a small neighbourhood

244 to an entire city. In CitySim detailed radiation models for solar and longwave radiation are imple-

245 mented that can account for the radiation exchange between neighbouring buildings, the ground and

246 environment. The Perez All Weather (Perez et al. 1993) and the Simple Radiosity algorithm (Rob-

247 inson and Stone 2006) are used to compute hourly irradiations of short and longwave radiation on

248 building surfaces. Multiple iterations for the radiation calculations are performed to achieve con-

249 sistent results. The heat flow through the walls is determined with a model based on the analogy

250 with an electrical circuit (resistor-capacitor network). The windows are considered as a building

251 surface, but not represented geometrically, therefore no window surface temperature is determined

252 and the temperature of the wall is used for the whole surface. This has an advantage for the study

253 presented in this paper, because the geometrical details of the windows are not defined for design A

254 and design B. For the convective heat transfer coefficients (CHTC) CitySim uses the correlations by

255 McAdams (1954). CitySim uses an hourly timestep, which cannot be changed. With CitySim build-

256 ings can be modelled as single- and multi-zone buildings. CitySim also includes HVAC and energy

257 conversion system models (Robinson 2011). CitySim determines the heat balances for all building

258 materials and for the ground. The ground heat balance includes short and longwave radiation and

259 storage of heat as well as heat conduction to the soil. To model the heat storage and heat conduction

260 of the ground, a number of ground layers are defined with the thickness, the heat conductivity and

261 the heat capacity as input parameters.

262

263

264

265

266

267

268

269

270

271

272

273

274

275

276

277

\subsection{CFD}

To study the urban microclimate, 3D steady RANS (Reynolds-Averaged Navier-Stokes) CFD simulations are conducted with a realizable k- $\varepsilon$ turbulence model with OpenFOAM. To account for buoyancy the Boussinesq approximation is used. Second-order discretization schemes as well as the SIMPLE algorithm for pressure-velocity coupling are employed. Pressure interpolation is of second order.

\section{Results and Discussion}

\subsection{Surface Temperatures}

First the surface temperatures of the buildings are analysed, which are later used as boundary conditions for the CFD simulations. In Figure 4 and 5 surface temperatures are given from two viewing directions. The results are given for both design options and two albedos ( 0.2 and 0.6$)$. The surface temperatures and the distribution of the surface temperatures for façades with different orientations are very similar for the two designs, because the surface temperatures are mainly dependent on the building materials, which are the same for the two designs. The building designs could be optimised using shadowing to reduce the surface temperatures, but both designs do not take advantage of shadowing effect, therefore no large differences in surface temperatures for the two designs could 
be expected. This confirms the finding of Allegrini et al. 2015a for more generic building geometries. They showed that the temperatures are rather similar for buildings with similar geometry, building materials and distances from the neighbouring buildings.

\section{Design A}

\section{Design B}
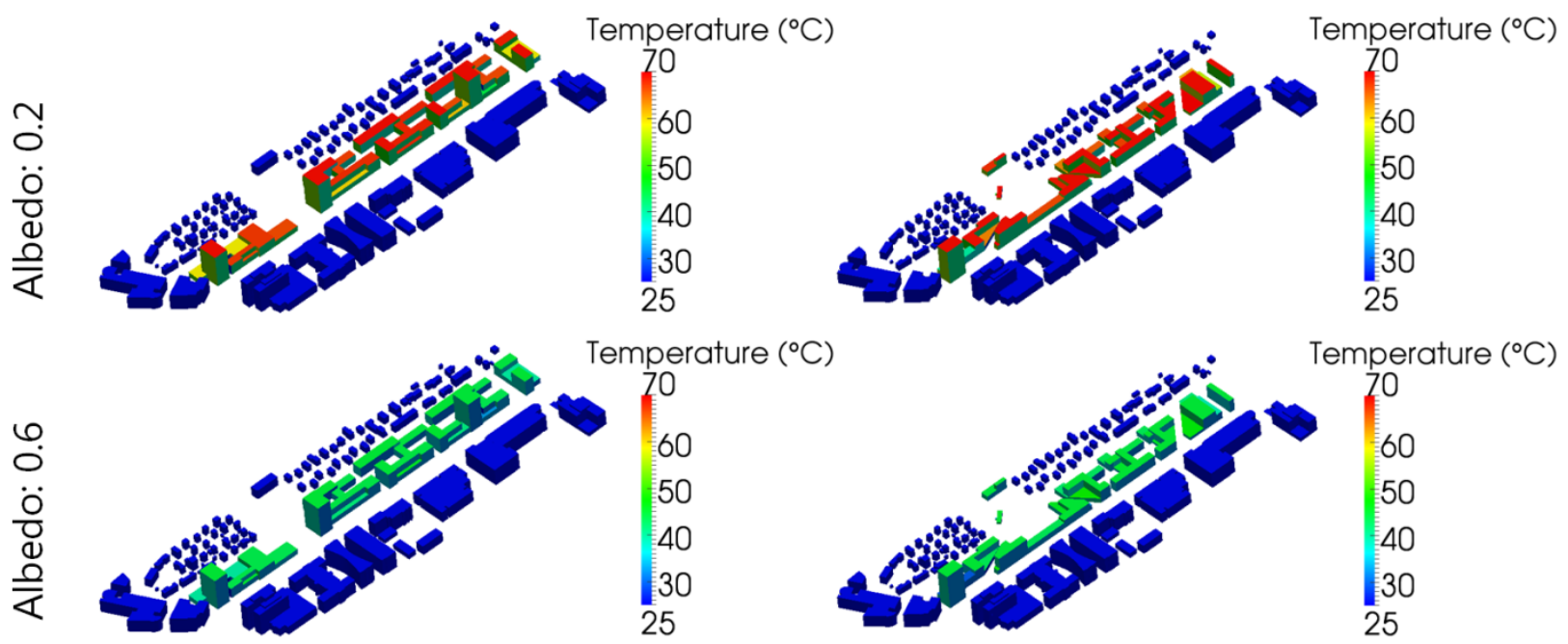

Temperature $\left({ }^{\circ} \mathrm{C}\right)$

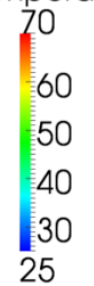

Figure 4: Surface temperatures simulated with BES.

The albedo has a large impact on the surface temperatures. For this case study two extreme values for the albedos are chosen. For the cases with highly absorbent materials surface temperatures of up to $70{ }^{\circ} \mathrm{C}$ can be found, while the highest surface temperatures for the highly reflective materials are about $45{ }^{\circ} \mathrm{C}$. The highest surface temperatures can be found on the building roofs for all cases. Rather high surface temperature differences of about $25^{\circ} \mathrm{C}$ exist between the sunlit façades and the unlit façades. In Figure 5 the shadowing effect of the towers on the surrounding roofs can be observed.

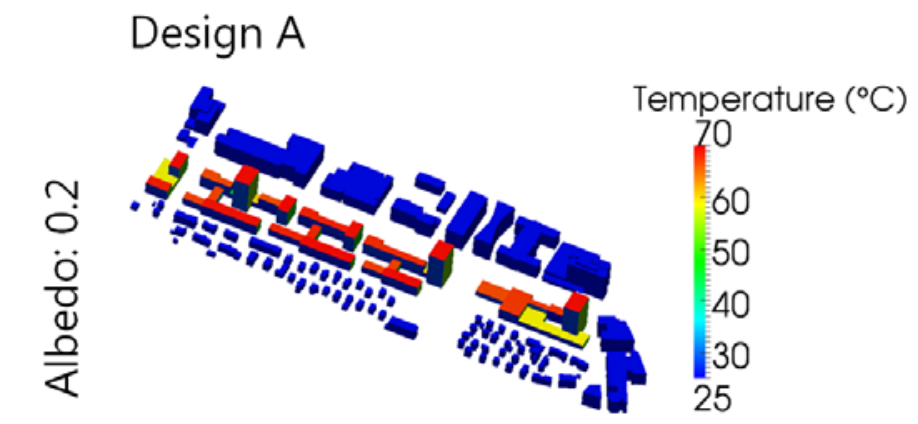

\section{Design B}
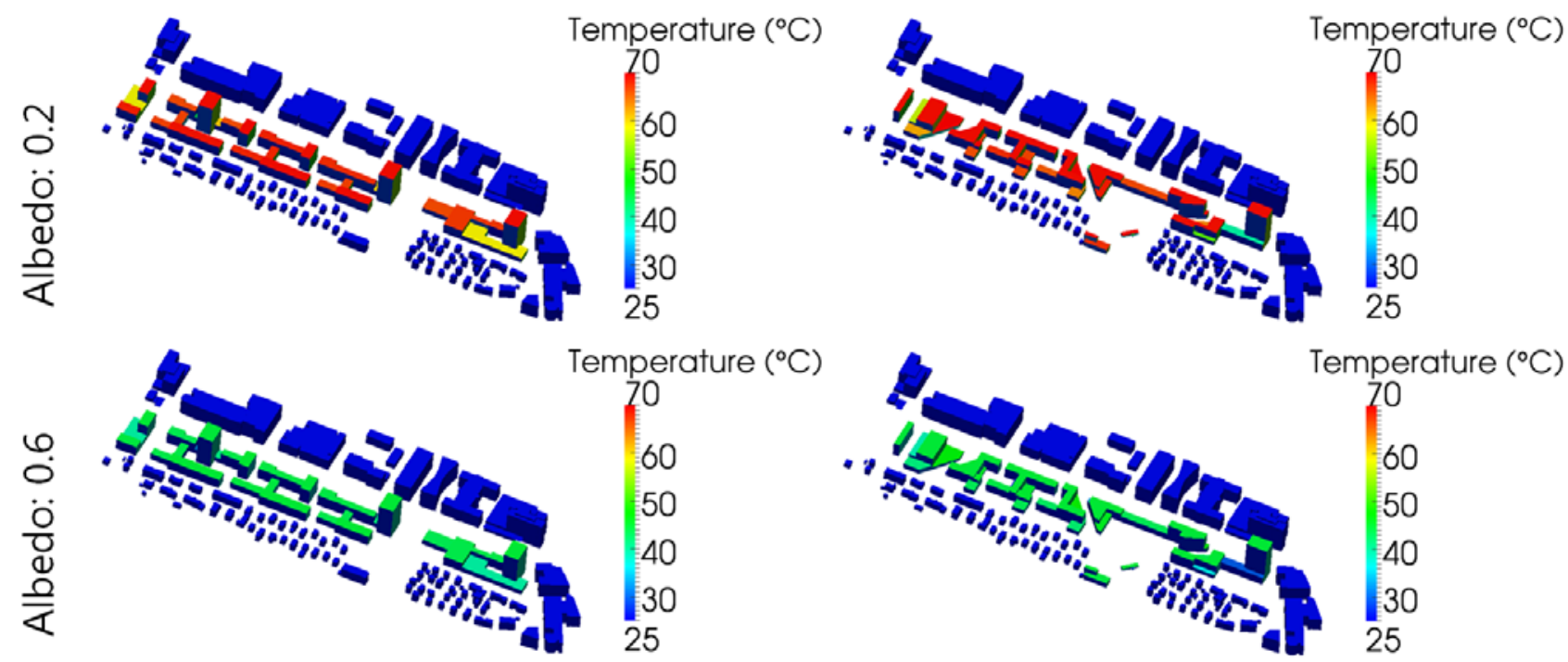

Figure 5: Surface temperatures simulated with BES. 
The results of this section show that the individual surface temperatures can independently be influenced by the choice of the building materials and by optimising the building geometries to use shadowing effects. The surface temperatures impact the local microclimate in different ways. The air reaches higher values close to surfaces with higher surface temperatures due to the higher convective heat transfer. Higher surface temperatures decrease the thermal comfort of pedestrians in summer due to the increased thermal radiation (Fiala et al. 2012). Generally, when choosing the albedo in urban areas, one has to consider that with higher albedos the solar irradiation on the neighbouring buildings due to reflection is also increased. If no shading devices are used, this can lead to higher solar gains in the neighbouring buildings (Allegrini et al. 2016). Finally, high surface temperatures due to low albedo values could induce strong buoyancy effects, which change the flow fields and could increase the removal of heat (Allegrini et al. 2015a and Allegrini et al. 2015b).

\subsection{Air Temperatures}

Due to the convective heat transfer at the building façades, the surface temperatures have an influence on the local air temperatures in the vicinity of the buildings. Figures 6-8 depict the temperature differences between the local and ambient air temperatures $2 \mathrm{~m}$ above the ground. As explained above, these temperature differences can be understood as the potential temperature increase caused by the presence of the new buildings. It is important to remark that only local (small scale) heat islands are considered here, while the global urban heat island is neglected. This is possible since only temperature differences and not absolute values are studied. Therefore the temperature differences between the local air temperatures and the rural temperatures would be even higher.
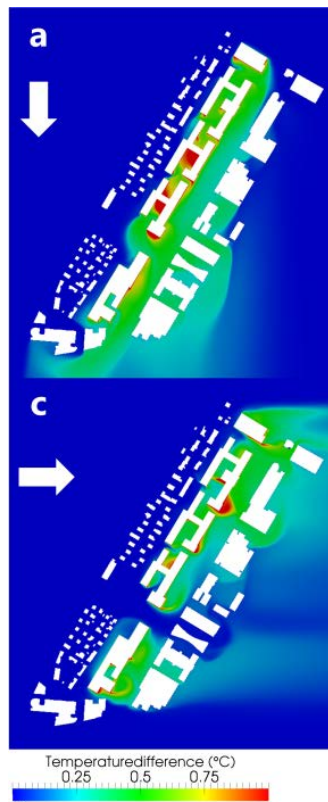

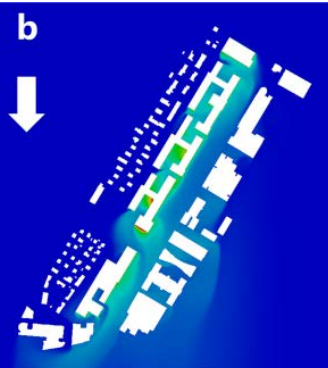

d

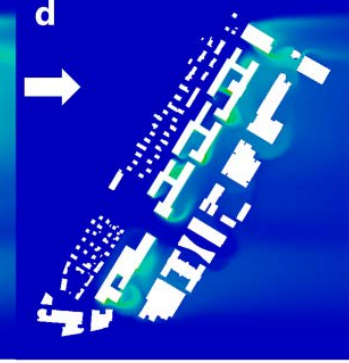

Figure 6: Temperature differences between the local and the ambient air temperature $2 \mathrm{~m}$ above the ground for design A. The wind speed is $5 \mathrm{~m} / \mathrm{s}$ (10 $\mathrm{m}$ above the ground). The results are presented for two albedos: $0.2(a, c)$ and $0.6(b, d)$. 


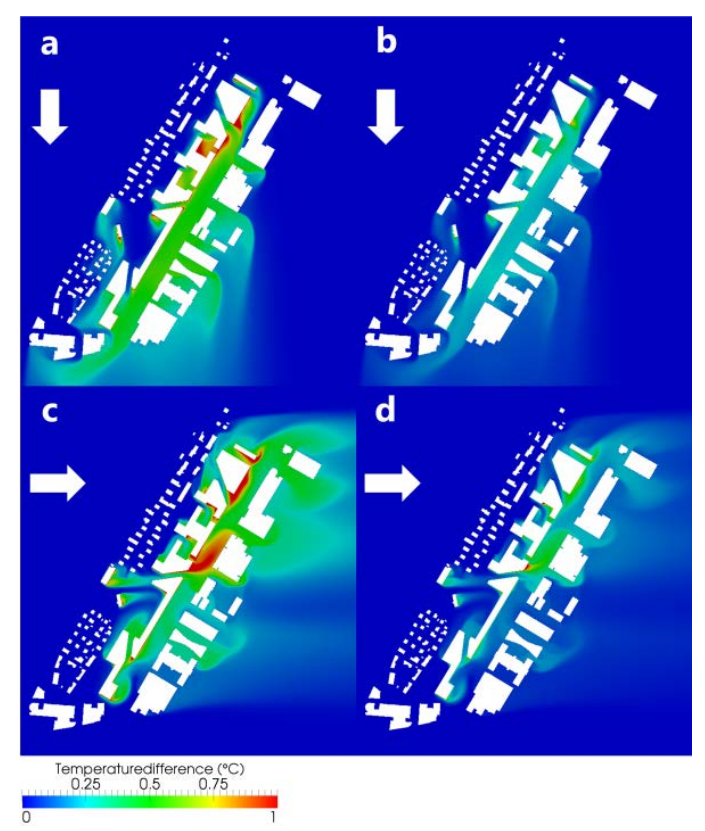

Figure 7: Temperature differences between the local and the ambient air temperature $2 \mathrm{~m}$ above the ground for design $B$. The wind speed is $5 \mathrm{~m} / \mathrm{s}$ (10 $\mathrm{m}$ above the ground). The results are presented for two albedos: $0.2(a, c)$ and $0.6(b, d)$.

The results in Figures 6-8 show that the air temperatures at the building site can locally increase by about $1{ }^{\circ} \mathrm{C}$ on a summer afternoon due to the construction of new buildings. In Figure 6 the temperature differences are given for the design A with a wind speed of $5 \mathrm{~m} / \mathrm{s}$ at $10 \mathrm{~m}$ height. The results are given for two wind directions and two albedo values. While the different wind directions lead to local urban heat islands at different locations with about the same intensity, the higher albedos significantly reduce the local heat island intensities for both wind directions. The highest temperature differences for an albedo of 0.2 is about $1{ }^{\circ} \mathrm{C}$ and for an albedo of 0.6 only about $0.5^{\circ} \mathrm{C}$. The lower air temperatures for higher albedos are caused by the lower building surface temperatures and therefore lower convective heat transfer. High local heat island intensities can mostly be found in areas that are highly surrounded by buildings. These areas are not well ventilated by wind. Comparing Figure 6a with Figure 6c, it can be seen that the ventilation of such areas can be strongly dependent on the wind direction. One of the areas with a courtyard shape has much higher local heat island intensity in Figure 6a compared to Figure 6c. In Figure 6c local heat islands downwind of the buildings can be found. These are caused by standing vortices that trap the air in the street canyon. In the same figure it can also be seen that the ventilation is improved by having an open space between the existing and new buildings, where the air can enter the building site and flow into the street canyon. In Figure 7 the same results as in Figure 6 are presented for the design B. Also for design B the albedos have a large impact on the local microclimate. As for design A a local heat island can be found for northerly wind directions in an area that is surrounded by buildings. There is a second similar area, where also a high local heat island intensity could be expected. But in that area the air temperatures are significantly lower. The detailed flow structures in these courtyards are presented in Figure 12 (see below). For design B the local heat island are larger for westerly compared to nor- 
therly wind directions. For this case the larger local heat island mainly forms due to the fact that the street canyon is not well ventilated for westerly wind directions, because the existing buildings downstream of the building site block the wind flow. This shows that street canyons that are formed by a number of individual buildings with small distances between the buildings perform similar as street canyons that are formed by two very long buildings, which are often used in studies with generic building geometries (e.g. Allegrini et al. 2015a).

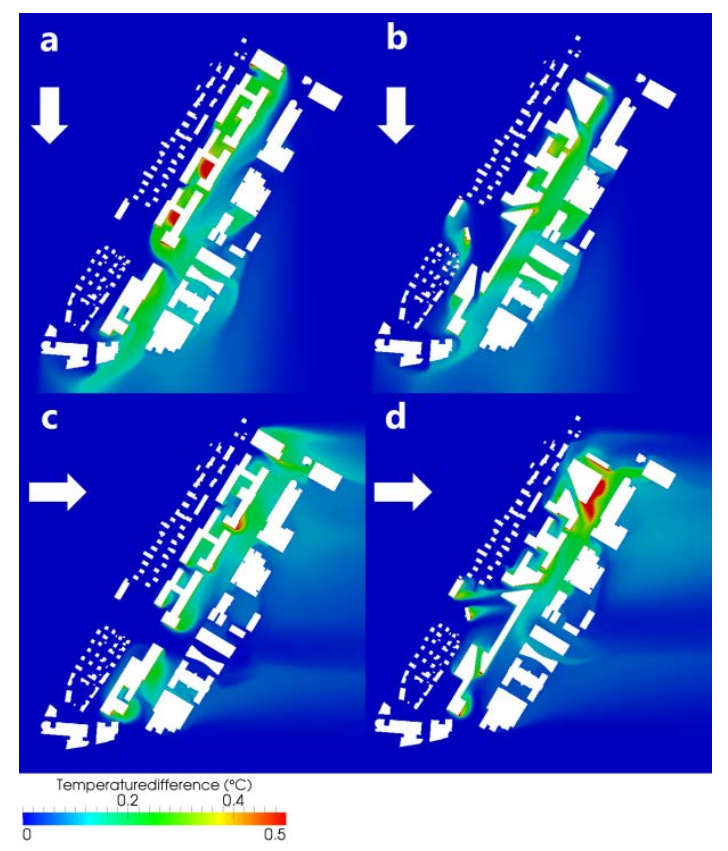

Figure 8: Temperature difference between the local and the ambient air temperature $2 \mathrm{~m}$ above the ground for design $A(a, c)$ and $B(c, d)$. The wind speed is $1 \mathrm{~m} / \mathrm{s}(10 \mathrm{~m}$ above the ground). The albedo is 0.6.

In Figure 8 results from the simulations with $1 \mathrm{~m} / \mathrm{s}$ wind speeds at $10 \mathrm{~m}$ height are presented. Design A performs similar for low compared to high wind speeds. The local heat islands are a bit smaller for lower wind speeds, because the ventilation is increased due to stronger buoyancy effects. Due to buoyancy there is an upwards flow from the urban area to the environment for lower wind speeds (also shown by Allegrini et al. 2015a and Allegrini et al. 2015b). Therefore more heat is removed and more cold air can enter the urban area from the sides. This effect is even more pronounced for design B. These effects are discussed in more detail in section 5.3.The large local heat island in the street canyon that exists for the higher wind speeds is strongly reduced in size for the lower wind speeds.

In Figure 9 the temperature differences between the ambient temperature and the local temperatures are given on a vertical plane in the centre of the street canyon for design $\mathrm{B}$ and two different wind speeds $(1 \mathrm{~m} / \mathrm{s}$ and $5 \mathrm{~m} / \mathrm{s}$ at $10 \mathrm{~m}$ height). For the lower wind speed case the highest air temperatures are mostly not found close to the ground, because the warm air is moving upwards. The warm air is moving upwards in plumes. Therefore the warm air rises higher in plume regions compared to other regions. For the higher wind speed case the height that the warm air reaches is more uniform and 
mostly influenced by the building height of the upstream buildings. The warmer air does not reach the same height as the warm plumes for the lower wind speed case. In the higher wind speed case the regions with higher air temperatures are mostly situated close to the ground. Due to the higher wind speeds, the flow is in a more forced convective regime and the warmer air cannot move upwards due to buoyancy. This explains why higher air temperature can be found close to the ground for the higher wind speed case compared to the lower wind speed case.

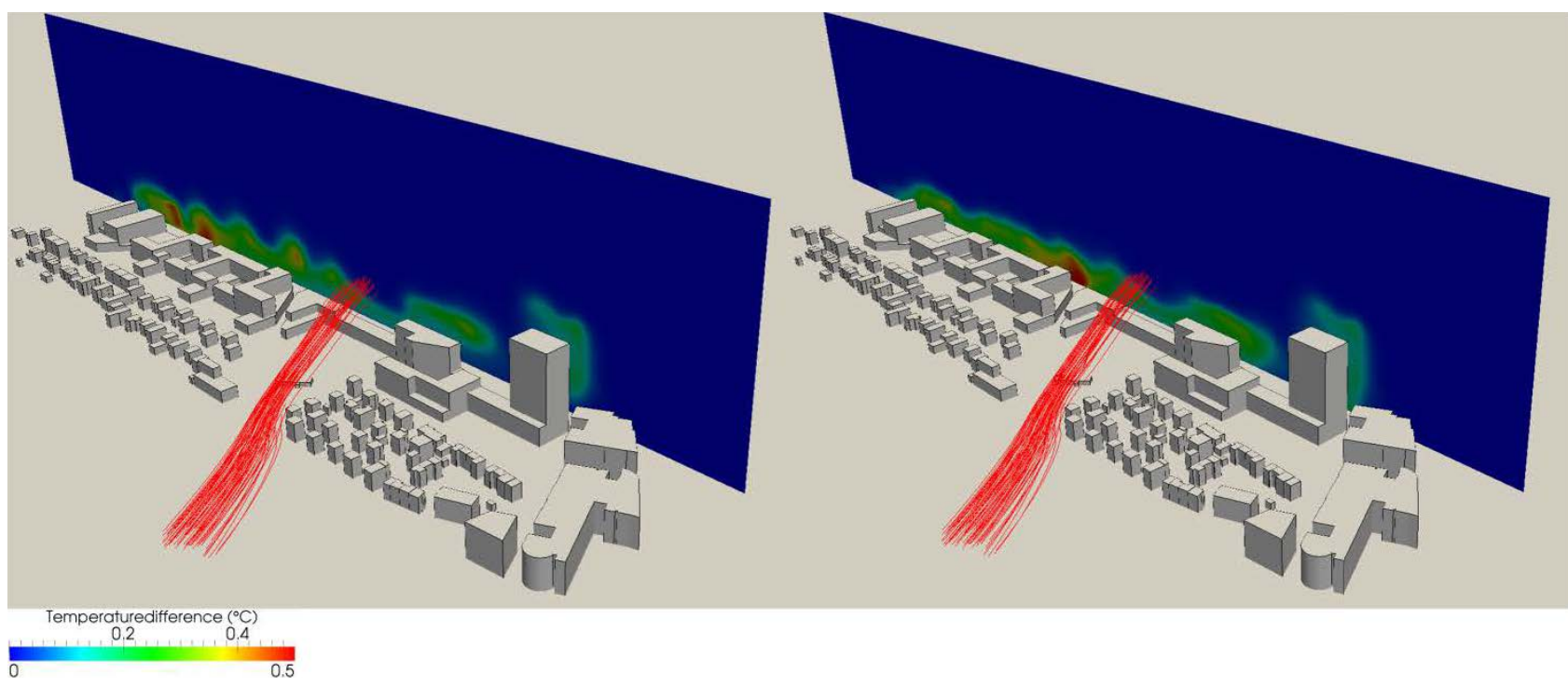

Figure 9: Temperature difference between the local and the ambient air temperature on a vertical plane in the centre of the street canyon for design $B$. The albedo is 0.6. The wind speed is $1 \mathrm{~m} / \mathrm{s}$ (10 $m$ above the ground) for the left figure and $5 \mathrm{~m} / \mathrm{s}$ for the right figure. The red streamlines indicate the wind direction (West).

Figure 10 shows temperature differences between the local and the ambient air temperature $2 \mathrm{~m}$ above the ground as well as contour plots of a temperature difference of $0.5^{\circ} \mathrm{C}$ for design $\mathrm{A}$ and $\mathrm{B}$. This means that within the contours given in Figure 10 the local heat island intensity is larger than $0.5^{\circ} \mathrm{C}$. In Figures 4 and 5 it could be seen that the highest surface temperatures can be found on the roofs. The results in Figure 10 show that the highest local air temperature can also be found at the roof level. In Figure 10c is can be seen that the contours do not reach the ground in the street canyon and therefore the air temperatures are lower at the ground compared to the roof level. This has no direct impact on the thermal comfort of the pedestrian, but can influence the performance of the buildings. For example it can increase the space cooling demands, when warm air is taken in for building ventilation. For all cases studied here, the warmer air can flow over the neighbouring buildings. If the neighbouring buildings would be higher, the warm air might be forced to flow downwards into the street canyon, what would lead to higher air temperatures at the ground level. Figures 10a and 10c show that the opening between the rows of buildings for design A has a positive impact on the air temperature inside the street canyon. Colder air can flow through this opening into the street canyon and increases the ventilation. A similar effect can also be found for design B, 

the continuous local heat islands is larger for design $\mathrm{B}$ than design $\mathrm{A}$.
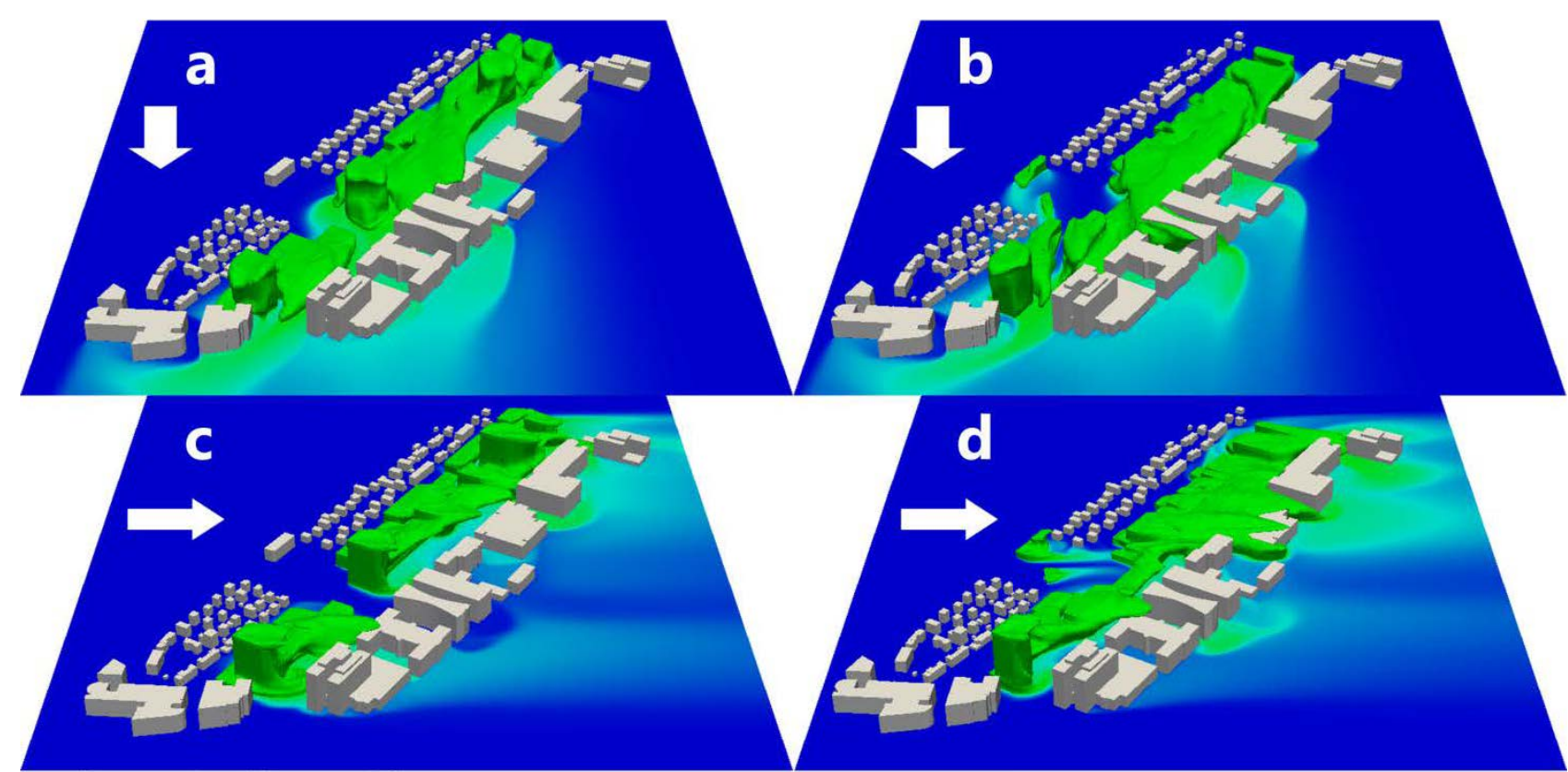

Temperaturedifference $\left({ }^{\circ} \mathrm{C}\right)$

396

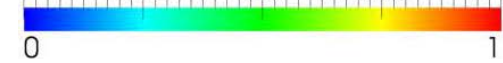

397

Figure 10: Temperature differences between the local and the ambient air temperature $2 \mathrm{~m}$ above the ground as well as contour plots of a temperature difference of $0.5^{\circ} \mathrm{C}$ for design $\mathrm{A}(\mathrm{a}, \mathrm{c})$ and $B(b, d)$. The wind speed is $5 \mathrm{~m} / \mathrm{s}$ (10 $\mathrm{m}$ above the ground). The albedo is 0.2 .

400

Figure 11 shows in addition to the temperature differences also the velocity vector fields projected on the horizontal plane $2 \mathrm{~m}$ above the ground. The results show that for northerly wind directions the wind is channelled through the street canyon and is able to remove heat. For westerly wind directions, corner flows are formed inside the street canyon and have a negative impact on the ventilation. The vortex structures are formed in regions, where the wind can enter the street canyons between the buildings. In Figure 11 it can also be seen that in regions, where there are corner flows, the air temperatures are higher, due to the entrapment of the air. This explains why stronger local heat islands can be found in the street canyon for westerly compared to northerly wind directions. 


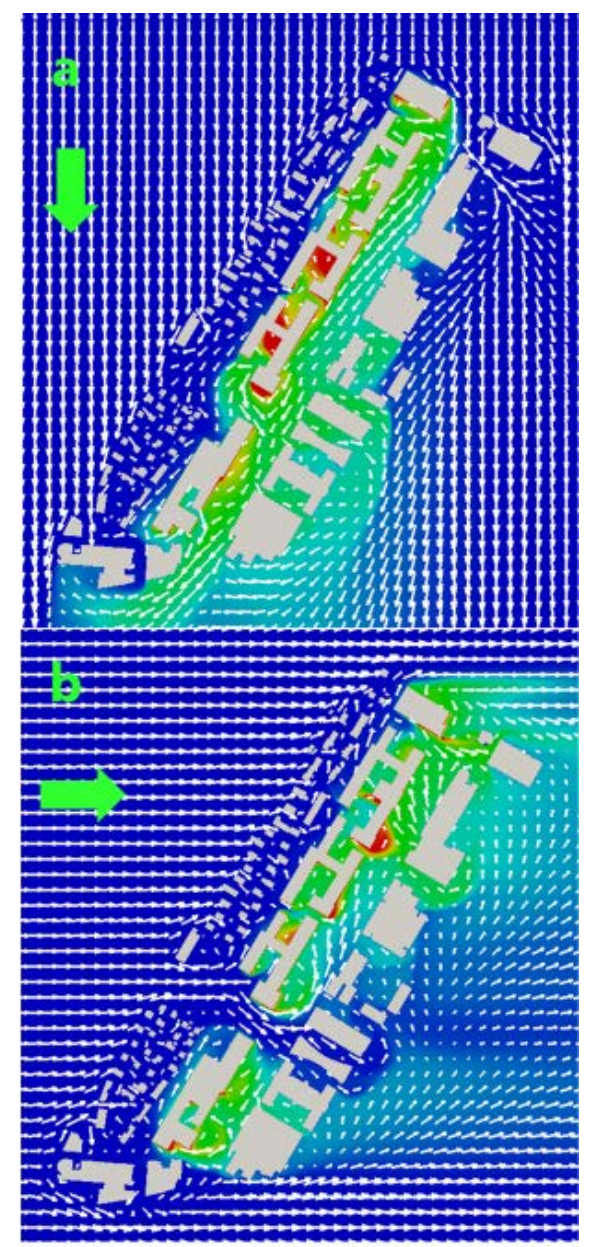

Temperaturedifference $\left({ }^{\circ} \mathrm{C}\right)$ 0

$\begin{array}{lll}0.25 & 0.5 & 0.75\end{array}$

Figure 11: Temperature difference between the local and the ambient air temperature and projected vector fields $2 \mathrm{~m}$ above the ground for design A. The wind speed is $5 \mathrm{~m} / \mathrm{s}(10 \mathrm{~m}$ above the ground).

The results in this section show the complexity of the phenomena that influence the local urban microclimate. Already small changes in wind speeds, wind directions or changes of building geometries or materials can have a large impact on the local air temperatures. Based on the temperature results presented in this paper, it cannot be concluded which of the two designs would lead to a better local microclimate on the pedestrian level of the building site. For some weather conditions design A performs better and for others design B performs better. A reason for the similar performance of the two designs is that the designs are rather similar. Due to the long and narrow buildings site the design options were rather limited.

\subsection{Flow fields}

There is a strong interaction between the local heat island intensities and the flow structures. To better understand the formation of local heat island the wind flow structures are studied in this section. Figure 12 depicts streamlines, which show the reason why in some courtyards high local heat island intensities can be found and in others the air temperatures are lower. For design A a strong heat is- 
land can be found in one of the courtyards (see also Figure 6a). Figure 12 shows that there is a strong vortex inside this courtyard and the warm air is trapped inside this vortex. There is only few air leaving the vortex, because there is a taller building downstream of the vortex and the air needs to flow over this building. The vortex forms exactly in the diagonal direction of the courtyard and is therefore very stable. In the two courtyards of design B (Figure 12 right) no strong vortexes but helical flow structures are formed. The air is trapped for shorter times in these helical flow structures and therefore heats up less, what is leading to lower local heat island intensities. For one of the courtyards the air is leaving the courtyard through an opening between the buildings and for the other courtyard the air is flowing over the roofs. For the latter courtyard the air is forced to flow over the roof, because there is a low-rise building inside the courtyard that forced the air in the helical flow structure to move upward from the ground. Based on the results in Figure 12 it can be concluded that small geometrical details can have a strong impact on the local air temperatures. Therefore, the conclusions of Allegrini et al. 2015a for courtyards have to be applied carefully, when the impact of courtyard-like building geometries are evaluated for complex instead of generic building configurations.

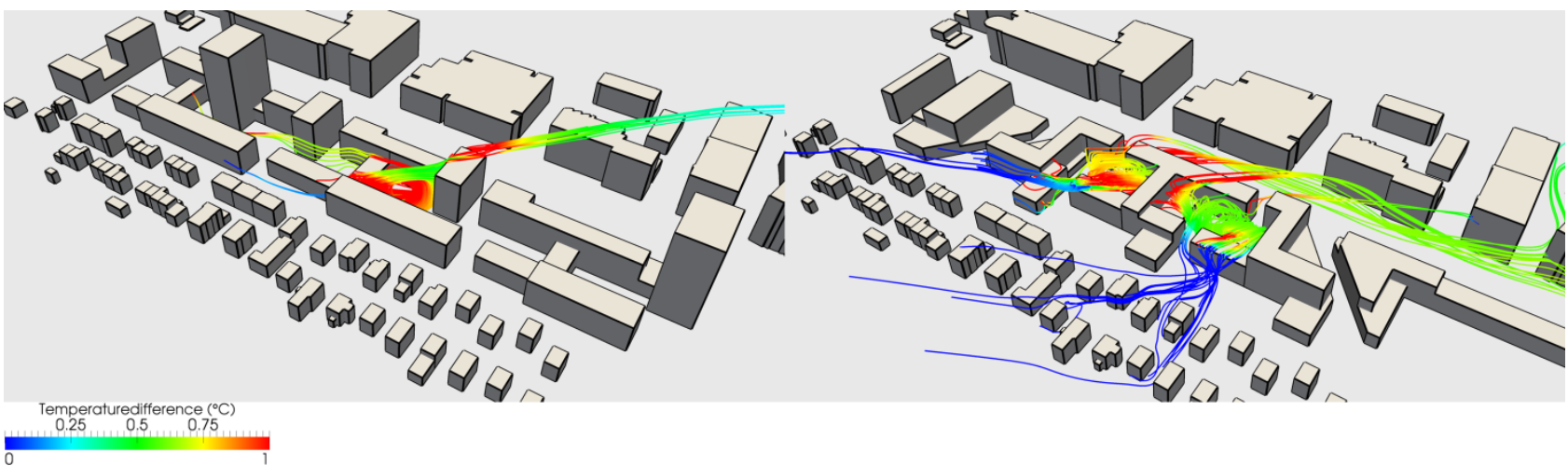

Figure 12: Streamlines for westerly wind direction for design A (left) and design B (right). The colours show the temperature difference between the local and ambient air temperature. The albedo is 0.2 and the wind speed is $5 \mathrm{~m} / \mathrm{s}$ (10m above the ground).

Figure 13 shows streamlines, which illustrate the reason for large local heat island found in Figure 7c. In Figure 13 (left) in can be seen the for the lower wind speed case the warm air inside the street canyon is moving upwards and further downstream flowing over the roofs of the neighbouring buildings. These upwards motions are induced by buoyancy effect. For the higher wind speed case in Figure 13 (right) the flow structure is significantly different. The air approaching from upstream is hitting the buildings downstream of the street canyon. There the air is forced to flow downwards. This downwards flow is forcing the warm air inside the street canyon to stay on the pedestrian level and a vortex is formed, where the warm air is trapped. This leads to a rather large local heat island with high intensity. For the higher wind speed case the buoyancy effects are not strong enough to force the warm air to move upwards and leave the urban area. This shows that buoyancy can have a positive impact on the local microclimate at pedestrian level. The results presented in this paper show that buoyancy in a complex urban environment with non-uniform building heights has a simi- 
lar impact on the local air temperatures as it has for the generic building configurations with uniform buildings heights used by Allegrini et al. 2015a and Allegrini et al. 2015b in their studies.

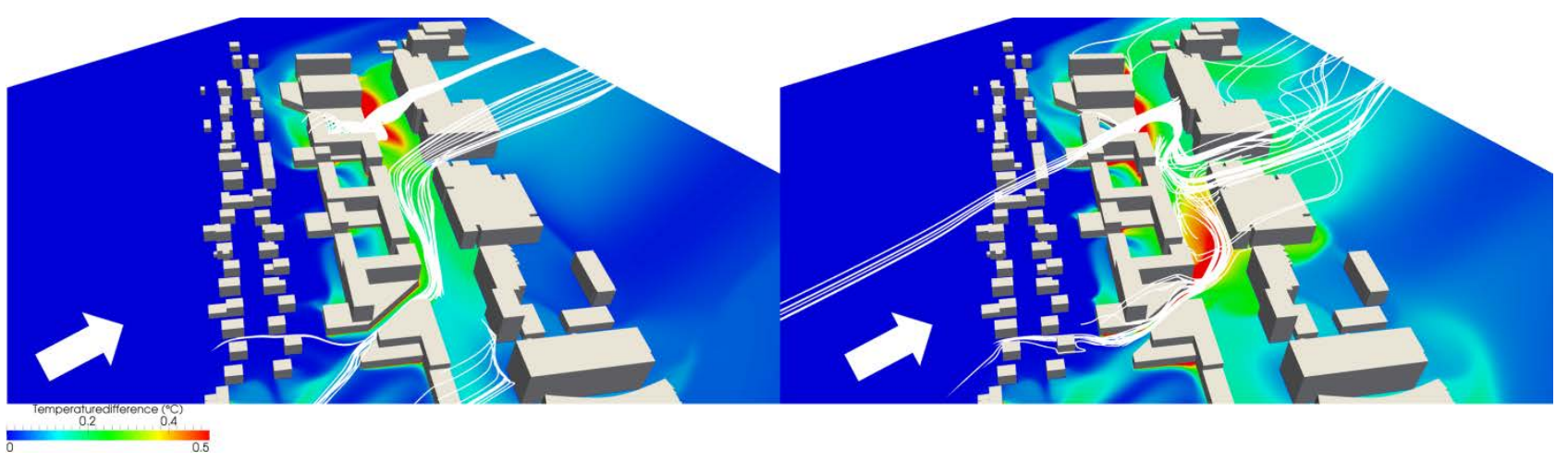

458

459

460

461

462

463

464

465

466

467

468

469

470

471

472

473

474

Figure 13: Streamlines for westerly wind direction for design B. The colours show temperature differences between the local and the ambient air temperature on a plane $2 \mathrm{~m}$ above the ground. The albedo is 0.2 and the wind speeds are $1 \mathrm{~m} / \mathrm{s}$ (left) and $5 \mathrm{~m} / \mathrm{s}$ (right) (10m above the ground).

Besides the air temperatures also the local wind speeds have an impact on the thermal comfort of pedestrians. Figures 14 and 15 show the local wind speeds at $2 \mathrm{~m}$ above the ground for eight different cases. Inside the urban areas the wind speeds are mostly decreased. The highest local wind speeds can be found in the street canyon and the opening between the rows of buildings for design A. Depending on the building geometries the wind speeds strongly change in the street canyon. For westerly wind directions increased wind speeds can be found in the street canyon at one of the corners of the middle tower indicated in red in Figure 14 (see also Figure 1). These corner streams around high-rise buildings are well known and can only be found for one corner of the three towers. For all cases also areas with very low wind speeds can be found in the street canyon. The strongest decrease of local wind speeds can be found in Figure 15d. In general the wind speeds in larger areas in the street canyon are comparable to the wind speeds outside the urban areas. Comparing Figures 14 and 15 with Figures 6-8 it can be concluded that there is often no clear correlation between the wind speed and the local air temperature. 


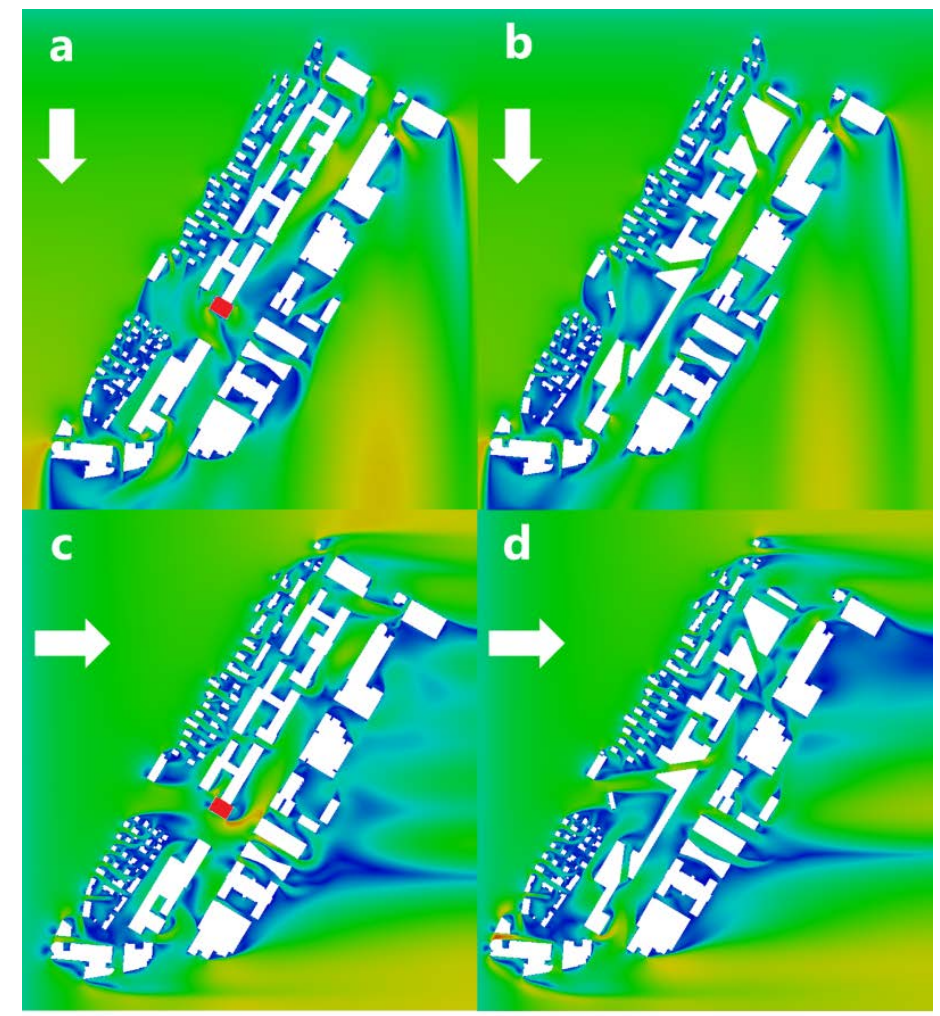

475

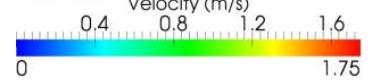

$476 \quad$ Figure 14: Local wind speed $2 m$ above the ground for design $A(a, c)$ and design $B(b, d)$. The wind $477 \quad$ speed is $1 \mathrm{~m} / \mathrm{s}$ (10 $\mathrm{m}$ above the ground). The albedo is 0.6 .
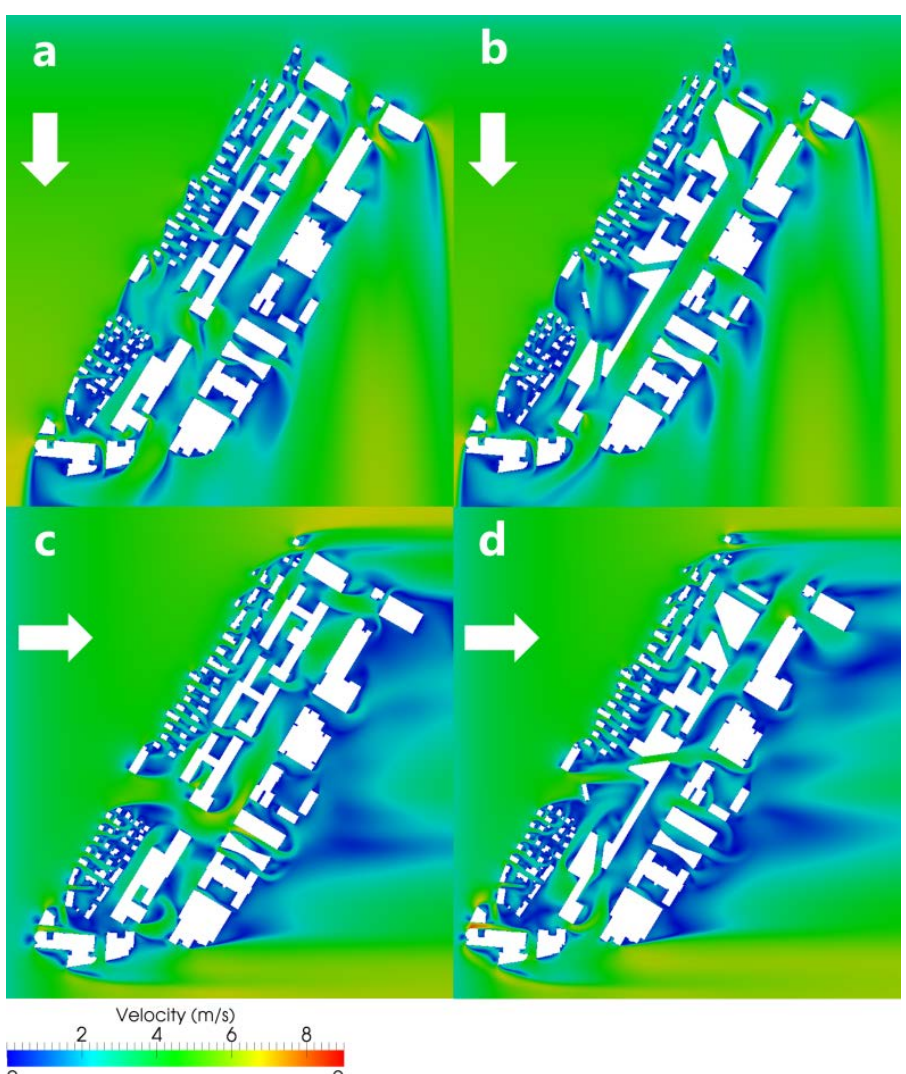
Figure 15: Local wind speed $2 m$ above the ground for design $A(a, c)$ and design $B(b, d)$. The wind speed is $5 \mathrm{~m} / \mathrm{s}$ (10 $\mathrm{m}$ above the ground). The albedo is 0.6 .

\section{Limitations}

In this paper the influence of different building geometries and materials on the local microclimate in an existing urban neighbourhood in Zürich (Switzerland) was investigated. The study shows interesting results on the formation of local heat islands, but the approach applied in this study has some limitations, which are discussed here. Only two wind directions were considered. With a larger number of wind directions the performance of the two designs could be evaluated in more detail. Possible impacts of traffic and vegetation on the microclimate were neglected. The large scale urban heat island effect was not taken into account, but has a strong impact on the actual values of local air temperatures. Also more complex building geometries should be used for the simulations. For example balconies and the detailed location of windows could have an impact on the local microclimate. This study has been conducted for only one climate (Zürich). It would be interesting to study the microclimate also for other more extreme climates.

The understanding of the local heat island formation could be improved by running time resolved CFD simulations (e.g. LES: large eddy simulations). Finally a two-way coupling, where the convective heat transfer coefficients from CFD are used in BES, could improve the predicted building surface temperatures.

The microclimate for two possible designs of buildings at a building site was simulated for different weather conditions. The aim was to evaluate the performance of the designs and decide based on the results, which design would lead to a more comfortable local microclimate. From the case study it has to be concluded that no such decision could be made, because the performance of the designs is strongly dependent on the weather conditions and none of the designs performed clearly better for a large number of weather conditions.

\section{Conclusions}

A case study, where the urban microclimate at a building site is simulated with coupled CFD-BES simulations, is presented in this paper. The results show that in summer the building surfaces can reach very high temperatures. The surface temperatures can strongly be reduced by using building materials with high albedos. The albedo not only influences the surface temperatures, but also the air temperatures in urban areas. For the case study of this paper, the air temperature in an urban area could increase up to one $1{ }^{\circ} \mathrm{C}$ in summer, if additional buildings are built on a building site with an area of about 6.5 hectares. The rather low heat island intensity is explained by the fact that we simulate the increase in local heat island intensity created by the heating up of the air the building surfaces themselves, while we do not consider the heat island intensities created by the global UHI nor the heating up of the air by the city quarter surrounding the considered city block. This approach was chosen to study the impact of the new additional buildings on the local air temperatures inde- 
pendently. The CFD simulations show a strong influence of the local wind structures on the local heat island intensities. Local heat islands can mainly be found in areas, where open urban spaces are surrounded by buildings or where large vortex structures occur and therefore the site ventilation is reduced. The flow structures in the studied area are very complex. Not only the wind speeds and wind directions have a large impact on the local flow structures, but also the air temperatures influence the wind flow due to buoyancy.

Although a specific urban area in the city of Zürich (Switzerland) was studied, this specific study supports a number of more general conclusions, which can be drawn from the detailed urban microclimate analysis presented in this paper:

- Building surface temperatures can be strongly decreased by choosing building materials with high albedo values. The albedo values strongly influence the building surface temperatures and also the local outdoor air temperatures of areas between the buildings.

- Heat islands are formed very locally between buildings. Their formation is found to be highly dependent on the building geometry, the building materials used, wind direction and wind speed, studied in this paper.

- Buoyancy is especially important in urban areas, where wind speeds between buildings are rather low and the surface temperatures are high. For low wind speeds buoyancy can reduce the local heat islands, because the warm air can move upwards and be removed from the urban area.

- Heat is often entrapped in vortex structures and therefore local heat islands are often formed, where vortex structures are found.

- Local air temperatures close to the ground are mostly higher for high wind speeds compared to low wind speeds, because in the high wind speed case vortex structures are formed characteristic for a more forced convective flow regime. For low wind speeds plumes of warm air are formed and the warm air is more efficiently removed from the ground level by buoyancy.

- Openings between buildings or the presence of high-rise buildings in a lower building area can increase the ventilation and lead to lower local air temperatures.

- Comparing the results of this study with results from studies with generic building geometries show that the latter have to be used carefully, when evaluating the performance in terms of local microclimate of complex building configurations. Especially for courtyard-like geometries high care is needed, while street canyons might be less critical.

- The results of this case study show that the more complex geometries of city blocks and buildings lead to the appearance of local heat islands at different locations.

\section{Acknowledgments}




\section{References}

553

554

555

556

557

558

559

560

561

562

563

564

565

566

567

568

569

570

571

572

573

574

575

576

577

578

579

580

581

582

583

584

Ali-Toudert, F., Mayer, H. (2006). Numerical study on the effects of aspect ratio and orientation of an urban street canyon on outdoor thermal comfort in hot and dry climate. Building and Environment, 41, 94-108.

Allegrini, J., Dorer, V., Carmeliet, J. (2012a). Influence of the urban microclimate in street canyons on the energy demand for space cooling and heating of buildings. Energy and Buildings, 55, 823832.

Allegrini, J., Dorer, V., Carmeliet, J. (2012b). An adaptive temperature wall function for mixed convective flows at exterior surfaces of buildings in street canyons. Building and Environment, 49, 55-66.

Allegrini, J., Dorer, V., Carmeliet, J. (2015a). Influence of morphologies on the microclimate in urban neighbourhoods. Journal of Wind Engineering and Industrial Aerodynamics, 144, 108-117.

Allegrini, J., Dorer, V., Carmeliet, J. (2015b). Coupled CFD, radiation and building energy model for studying heat fluxes in an urban environment with generic building configurations. Sustainable Cities and Society, 19, 385-394.

Allegrini, J., Dorer, V., Carmeliet, J. (2016). Impact of radiation exchange between buildings in urban street canyons on space cooling demands of buildings. Energy and Buildings, 127, 1074-1084.

Arnfield, J. (2003). Two decades of urban climate research: a review of turbulence, exchanges of energy and water, and the urban heat island. International Journal of Climatology, 23, 1-26.

Bouyer, J., Inard, C., Musy, M. (2011). Microclimatic coupling as a solution to improve building energy simulation in an urban context, Energy and Buildings, 43, 1549-1559.

Bruse, M., Fleer, H. (1998). Simulating surface-plant-air interactions inside urban environments with a three-dimensional numerical model. Environmental Modelling Software, 13, 3737-384.

Fiala, D., Havenith, G., Bröde, P., Kampmann, B., Jendritzky, G. (2012). UTCI-Fiala multi-node model of human heat transfer and temperature regulation. International Journal of Biometeorology, $56(3), 429-441$.

Fischer, E.M., Schär, C. (2009). Future changes in daily summer temperature variability: driving processes and role for temperature extremes. Climate Dynamics, 33, 917-935.

Frank, T (2005). Climate change impacts on building heating and cooling energy demand in Switzerland. Energy and Buildings, 37, 1175-1185.

Franke, J., Hellsten, A., Schlünzen, H., Carissimo, B. (2011). The COST 732 best practice guideline for CFD simulation o flows in the urban environment: a summary. International Journal of Environment and Pollution, 44 (1-4), 419-427. 
Gromke, C.B., Blocken, B., Janssen, W.D., Merema, B., van Hooff, T., Timmermans, H.J.P., 2015. CFD analysis of transpirational cooling by vegetation: Case study for specific meteorological conditions during a heat wave in Arnhem, Netherlands. Building and Environment, 83, 11-26.

Haldi, F., Robinson, D. (2011). The impact of occupants' behaviour on building energy demand. Journal of Building Performance Simulation, 4 (4), 323-338.

Kämpf, J. (2009). On the modelling and optimisation of urban energy fluxes. $\mathrm{PhD}$ thesis $\mathrm{n}^{\circ} 4548$, EPF Lausanne, Switzerland.

Launder, B.E., Spalding, D.B. (1974). The numerical computation of turbulent flows. Computer Methods in Applied Mechanics and Engineering 3, 269-289.

Li, D., Bou-Zeid, E. (2013). Synergistic interactions between urban heat islands and heat waves: The impact in cities is larger than the sum of its parts. Journal of Applied Meteorology and Climatology, 52 (9), 2051-2064.

McAdams, W.H. (1954). Heat Transmission, McGraw-Hill Kogakusha, Tokyo.

Mirzaei, PA, Haghighat, F. (2010). Approaches to study urban heat island e abilities and limitations. Building and Environment, 45, 2192-2201.

Moonen, P., Defraeye, T., Dorer, V., Blocken, B., Carmeliet, J. (2012). Urban Physics: Effect of the micro-climate on comfort, health and energy demand. Frontiers of Architectural Research, 1, 197228.

Oke, T.R. (1987). Boundary Layer Climates, 2nd ed., Methuen, London, England.

Perez, R., Seals, R., Michalsky, J. (1993). All-weather model for sky luminance distribution preliminary configuration and validation. Solar Energy, 50 (3), 235-243.

Perini, K., Magliocco, A. (2014). Effects of vegetation, urban density, building height, and atmospheric conditions on local temperatures and thermal comfort. Urban Forestry and Urban Greening, $13(3), 495-506$.

Ramponi, R., Blocken, B., de Coo, L.B., Janssen, W.D. (2015). CFD simulation of outdoor ventilation of generic urban configurations with different urban densities and equal and unequal street widths. Building and Environment, 92, 152-166.

Richards, P.J., Hoxey, R.P. (1993). Appropriate boundary conditions for computational wind engineering models using the k- $\varepsilon$ turbulence model. Journal of Wind Engineering and Industrial Aerodynamics, 46-47, 145-153.

Robinson, D., Stone, A. (2006). Internal illumination prediction based on a simplified radiosity algorithm. Solar Energy, 80 (3), 260-267.

Robinson, D. (2011). Computer Modelling for Sustainable Urban design: Physical Principles, Methods and Applications, Earthscan, London. 
619 Robine, J.-M., Cheung, S. L. K., Le Roy, S., Van Oyen, H., Griffiths, C., Michel, J.-P., Herrmann, 620 F. R. (2008). Death toll exceeded 70,000 in Europe during the summer of 2003. Comptes Rendus 621 Biologies, 331, 171-178.

622 Saneinejad, S., Moonen, P., Defraeye, T., Derome, D., Carmeliet, J. (2012). Coupled CFD, radia623 tion and porous media transport model for evaluating evaporative cooling in an urban environment. 624 Journal of Wind Engineering and Industrial Aerodynamics, 104-106, 455-463.

625 Saneinejad, S., Moonen P., Carmeliet J. (2014). Coupled CFD, radiation and porous media model 626 for evaluating the micro-climate in an urban environment. Journal Wind Engineering and Industrial 627 Aerodynamics, 128, 1-11.

628 Santamouris, M., Papanikolaou, N., Livada, I., Koronakis, C., Georgakis, A. (2001). On the impact 629 of urban climate on the energy consumption of buildings. Solar Energy, 70 (3), p201-216.

630 Schär, C., Vidale, P.L., Lüthi, D., Frei, C., Häberli, C., Liniger, M.A., Appenzeller, C (2004). The 631 role of increasing temperature variability in European summer heatwaves. Nature, 427, 332-336.

632 SIA 2024, 2006. Standard-Nutzungsbedingungen für die Energie- und Gebäudetechnik, SIA, Swiss 633 Association of Engineers and Architects, Zürich.

634 Taleghani, M., Kleerekoper, L., Tenpierik, M., Van den Dobbelsteen, A. (2014). Outdoor thermal 635 comfort within five different urban forms in the Netherlands. Building and Environment, 83, 65-78.

636 Tominaga, Y., Mochida, A., Yoshie, R., Kataoka, H., Nozu, T., Yoshikawa, M., Shirasawa, T. 637 (2008). AIJ guidelines for practical applications of CFD to pedestrian wind environment around 638 buildings. Journal Wind Engineering and Industrial Aerodynamics, 96, 1749-1761.

639 Tominaga, Y. (2012). Visualization of city breathability based on CFD technique: case study for ur640 ban blocks in Niigata City. Journal of Visualization, 15, 239-276.

641 Toparlar, Y., Blocken, B., Vos, P., van Heijst, G.J.F, Janssen, W.D., van Hooff, T., Montazeri, H., 642 Timmermans, H.J.O (2015). CFD simulation and validation of urban microclimate: A case study for 643 Bergpolder Zuid, Rotterdam. Building Environment, 83, 79-90.

644 Van Hooff, T., Blocken, B. (2010). Coupled urban wind flow and indoor natural ventilation model645 ling on a high-resolution grid: A case study for the Amsterdam ArenA stadium. Environmental 646 Modelling and Software, 25, 51-65.

647 Walter, E., Kämpf, J. H. (2015). A verification of CitySim results using the BESTEST and moni648 tored consumption values. Proceeding of Building Simulation Applications BSA 2015, Bozen649 Bolzano, Italy.

650 Wanner, H., Hertig, J.-A. (1984). Studies of Urban Climates and Air Pollution in Switzerland. Jour651 nal of Climate and Applied Meteorology, 24, 1614-1625. 
652 Watkins, R., Palmer, J., Kolokotroni, M., Littlefair, P. (2002). The London Heat Island - results

653 from summertime monitoring. Building Services Engineering Research and Technology, 23 (2), 97 654106. 